\title{
COMPARISON OF OBJECT BASED MACHINE LEARNING CLASSIFICATIONS OF PLANETSCOPE AND WORLDVIEW-3 SATELLITE IMAGES FOR LAND USE / COVER
}

\author{
Aylin Tuzcu ${ }^{1}$, Gulsen Taskin², Nebiye Musaoğlu ${ }^{1}$ \\ 1. Istanbul Technical University, Faculty of Civil Engineering, Department of Geomatics Engineering, 34469 Maslak, \\ Istanbul TURKEY - (tuzcuay, musaoglune)@itu.edu.tr \\ 2. Istanbul Technical University, Earthquake Engineering and Disaster Management Institute, 34469 Maslak, Istanbul \\ TURKEY - tasking@itu.edu.tr
}

KEYWORDS: Remote sensing, Object Based Classification, Machine Learning, Land Use / Cover, Support Vector Machine

\begin{abstract}
:
The purpose of the study was to compare performance of the classification methods, that are Rule Based (RB) classifier and Support Vector Machine (SVM), of Planetscope and Worldview-3 satellite images in order to produce land use / cover thematic maps. Six classes, which are deep water, shallow water, vegetation, agricultural area, soil and saline soil, were considered. After performing the classification process, accuracy assessment was employed based on the error matrixes. The results showed that, both of the classification methods and satellite data were adequate to classify the area. Besides, classification accuracy was improved when Worldview-3 satellite and SVM method were used. The classification accuracies of RB classification of Planetscope and Worldview3 were $\% 87$ and \%94 respectively and the classification accuracies of SVM classification of Planetscope and Worldview-3 were \%93 and $\% 96$ respectively.
\end{abstract}

\section{INTRODUCTION}

There have been many various wetlands in Turkey. Konya Closed Basin (KCB), which is 4980534 ha area, is the third basin among 25 basins in Turkey. The wetlands in Konya Closed Basin have flora and fauna variety (CCIWR, 2016) Thus, as a pilot area, Akgol wetland and its around were selected. There have been many case studies conducted in this area. In a case study, water bodies of KCB were monitored from 1987 to 2017 by Landsat satellite data associated with meteorological data, a decrement in Akgol wetland area is observed as 96\% (Musaoglu et al, 2018). In another case study, adverse impacts of dam constructions on the study area were monitored by Landsat satellite images and meteorological data (Dervisoglu et al, 2017). In many case studies, Planetscope and Worldview images were used to extract detail information. Wicaksono and Lazuardi (2018) applied different object based classification methods to Planetscope satellite image to monitor benthic habitat and discriminate seagrass species. In addition, Wan and Chang (2018) applied support vector machines to Worldview-2 satellite image in order to determine different crop types. Xu (2013) indicates that rule based (RB) classifier divides data into smaller parts by defining rule sets iteratively. In one of the case studies related to application of RB method to Worldview-2 satellite image to extract urban information in detail and it was seen that the rule sets, which includes spatial, textural and spectral attributes, were transferable (Hamedianfar and Shafri, 2015).

\section{METHODS AND DATA}

\subsection{Study area}

Akgol wetland and its around located in Konya was chosen as a study area. It covers approximately 15634 ha consist of six types of land use / cover types, that are deep water, shallow water, vegetation, agricultural area, soil and saline soil. The location of study area and the satellite data are shown in Fig.1.

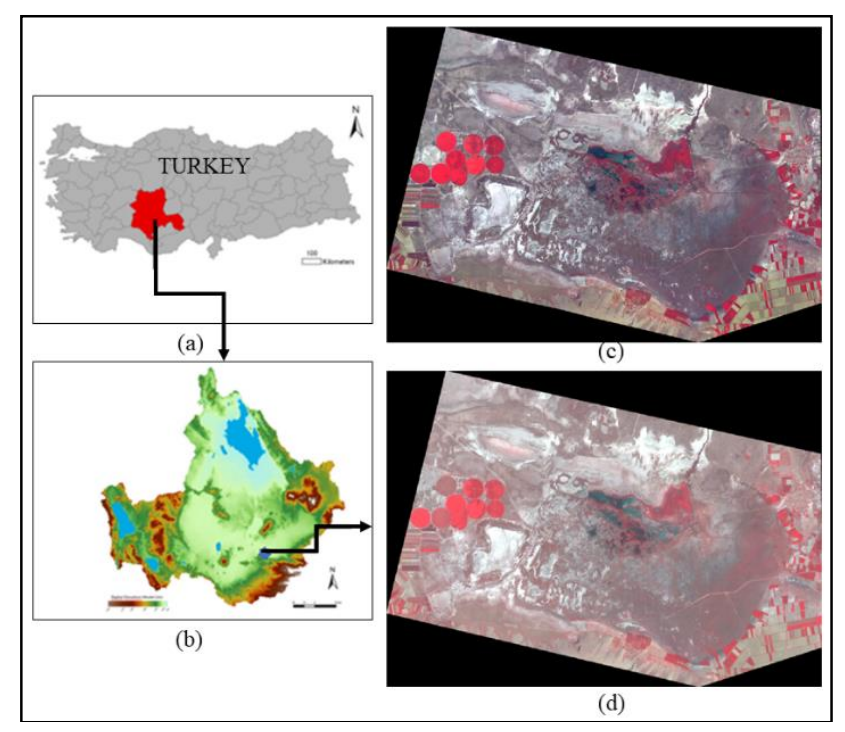

Figure 1. Study area a) Turkey b) Konya Closed Basin c) Worldview-3 Satellite Image d) Planet Satellite Image

\subsection{Dataset}

The data used in the study can be categorized into two sections: field and satellite data.

\subsubsection{Field Data}

It must be aimed that a field survey must be synchronized with the overflight of the satellite image sensor (McCoy, 2005). In situ measurements were conducted on May 4, 2018 by using GPS and field spectroradiometer. The samples were collected by field 
survey on May 4, 2018. The model of spectroradiometer is FieldSpec HH and its spectral range is between $325-1075 \mathrm{~nm}$. Photos, spectral reflectance and locations of one of water samples, belonging to shallow water, and one of soil samples are shown in Fig.2 and Fig.3.

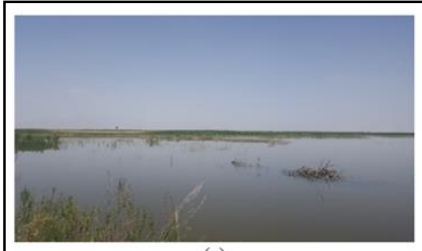

(a)

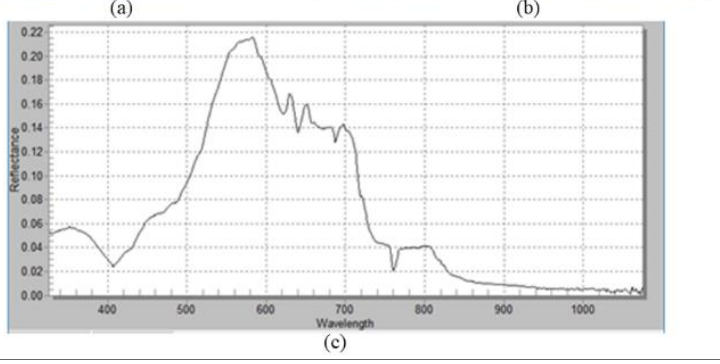

Figure 2: a) Water area in Akgol region b) Location c) Spectral reflectance of water

That water area belongs to shallow water. It is seen in Fig 2.c that there is maximum reflectance in green region and minumum reflectance in NIR region. That situation is compatible with the spectral signature of water. However, there is little reflectance in NIR region, because of being shallow.

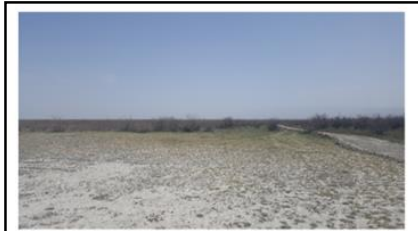

(a)

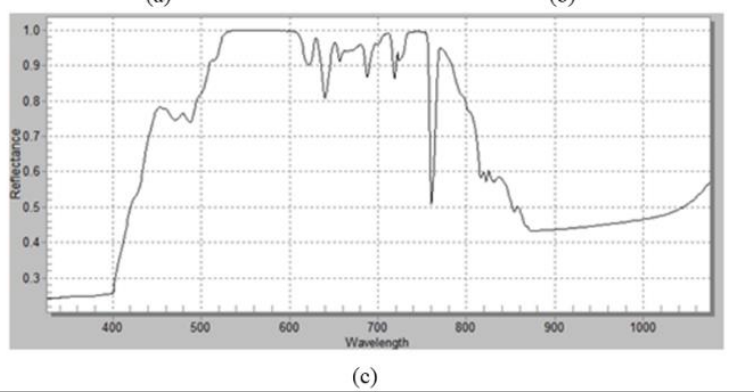

Figure 3: a) Soil b) Location c) Spectral reflectance of soil

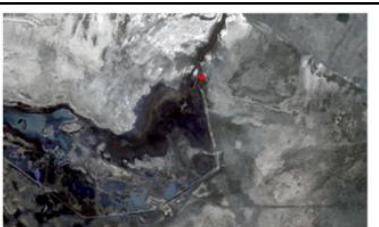

(b)
It is seen that the reflectance of soil increases in visible region and decreases in NIR region (Fig.3c). The reason of reflectance decreament in NIR region is being humid soil and close to water area.

\subsubsection{Satellite Data}

In order to extract detail information from the study area, high resolution satellite images are required. For this reason, using
Worldview-3 satellite image was aimed. However because of the cloudy weather conditions on field survey day, cloudless image of Worldview-3 satellite was not obtained. Although the weather condition in the day of field survey was cloudy, cloudless image was obtained by means of Planet constellation. The two main advantages of Planet satellites are to capture entire world daily and to provide cloudless images. The distances between doves were arranged according to monitor earth without gap (Kääb et al, 2017). STAIR technique is used to fuse the different satellite data belonging to various sources to produce cloudless, high spatial and temporal resolution images (Luo et al, 2018). Although it has lower spatial and spectral resolution than Worldview-3 satellite image, it gives information about the field survey day. Thus, it has supplemental quality.

Worldview-3 satellite image was acquired on May 18, 2018. It has 8 spectral bands which are coastal, blue, green, yellow, red, red edge, NIR1 and NIR2. The spatial resolution of multispectral bands and panchromatic band of Worldview-3 satellite image is $2.0 \mathrm{~m}$ and $0.5 \mathrm{~m}$ respectively. It was obtained in "Ortho Ready Standard 2A (OR2A)" level, which was corrected radiometrically and geometrically (Url-1).

Worldview-3 satellite image was acquired on May 4, 2018. Planetscope satellite image belongs to Planet Imagery. It has 4 spectral bands, which are blue, green, red and NIR, with $3.0 \mathrm{~m}$ spatial resolution. It was obtained in $3 \mathrm{~B}$ level, which was corrected radiometrically and geometrically (Url-2).

The datum and projection of both images were identified as WGS84 and UTM Zone 36N.

\subsection{Methodology}

Two types of object based classification methods were applied to Planetscope and Worldview-3 satellite images to discriminate six classes, which were deep water, shallow water, vegetation, agricultural area and two different type of soils. These classification methods were Rule Based classifier and support vector machine. A segmentation process was conducted as an initial step of the object based classification. In the segmentation step, satellite image was divided into some sub-areas, called as segments, based on the spectral information (Aguilar et al, 2013). There have been various segmentation types among of which, multi resolution segmentation has an advantage which is increasing individual homogeneity and decreases mean heterogeneity. Therefore, multi resolution segmentation was chosen as a segmentation type. The result of segmentation process varies according to three main criteria; homogeneity, color, shape, smoothness and compactness (Xian, 2015). These parameters can empirically be determined (Mathieu et al, 2007). The flow chart related to whole process is given in Fig.4.

Rule sets were generated by using spectral indices and shape attributes, after completing the segmentation process. The band combinations in these spectral indices varied according to the spectral range of two different satellite images. The indices, given in Eq. (1)-(4), that are NDWI (Normalized Difference 


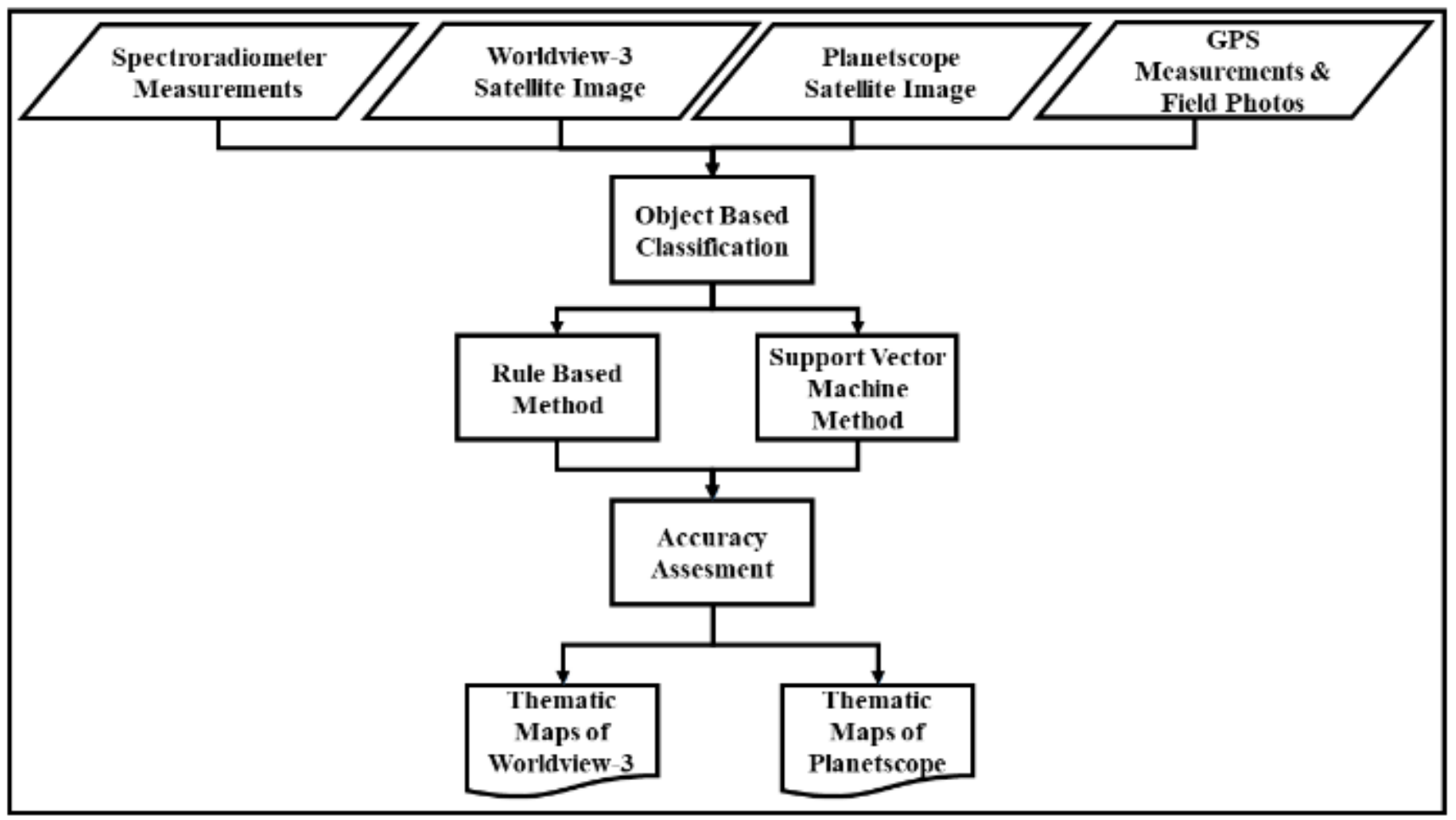

Figure 4. Flow chart considered in this study.

Water Index), NDVI (Normalized Difference Vegetation Index), SAVI (Soil Adjusted Vegetation Index) and SI (Salinity Index) were applied to Planetscope image. The water and the vegetation areas were determined by using NDWI and NDVI, respectively. The index, SAVI was utilized to discriminate the soil areas. The parameter L in SAVI formulation changes according to vegetation amount on the soil area. If there is a sparse vegetation, $\mathrm{L}$ parameter is taken as 1 . If there is a medium vegetation, $\mathrm{L}$ parameter is taken as 0.5 (Huete, 1988). Based on that information, L parameter was selected as 1 to separate soil class in the study. By using the index, SI, saline soil was determined. The shape attributes, roundness and rectangular fit, were used together to separate the vegetation and agricultural area classes.

$\mathrm{NDWI}=\frac{(\text { Green Band }- \text { NIR Band })}{(\text { Green Band }+ \text { NIR Band })} \quad($ McFeeters, 1996) $(1)$

$$
\begin{aligned}
& \text { NDVI }=\frac{(\text { NIR Band }- \text { Red Band })}{(\text { NIR Band }+ \text { Red Band })} \quad(\text { Rouse et al, 1974) }) \\
& \text { SAVI }=\frac{(\text { NIR Band }- \text { Red Band })}{((\text { NIR Band }+ \text { Red Band }+\mathrm{L})} *(1+L) \quad(\text { Huete, } 1988)(3)
\end{aligned}
$$$$
\text { SI }=\sqrt{(\text { Green } * \text { Red })}
$$$$
\text { (Douaoui et al, 2006) (4) }
$$

In a similar way, the indices, formulated in Eq. (5), (6), and (7), (4), NDWI, NDVI, NDSI (Normalized Difference Soil Index) and SI, were applied to Worldview-3 image. The advantages of using additional bands, coastal, yellow, red edge and NIR2, have been searched in many case studies. Based on the case studies, more efficient water indices can be generated to accurately determine the water areas by using the coastal band (Puetz et al, 2009). Because of having high reflectance in the red edge region, red edge band is an efficient tool to detect the vegetation areas (Forkuor et al, 2018). Wolf 2012 studied on utilizing different band combinations in classification of Worldview-2 image. In another case study, NDWI was examined by different band combinations and it was observed that by applying coastal and NIR2 band combination, more accurate results were obtained (Xie et al, 2016). Based on this research, NDWI was applied with coastal NIR2 band combination. Because of having difference reflectances of soil in green and yellow region, NDSI was generated to extract soil information (Wolf, 2012). NDVI was used with red edge and NIR2 band combination (Mutanga et al., 2012). SI was used to determine soil type 2 . Separation between vegetation and agricultural area classes were carried out by using the shape attributes.

$$
\begin{aligned}
& \text { NDWI }=\frac{(\text { Coastal Band }- \text { NIR2 Band })}{(\text { Coastal Band }+ \text { Yakın IR2 Band })} \\
& \text { NDVI }=\frac{(\text { NIR2 Band }- \text { Red Edge Band })}{(\text { NIR2 Band }+ \text { Red Edge Band })} \\
& \text { NDSI }=\frac{(\text { Green Band }- \text { Yellow Band })}{(\text { Green Band }+ \text { Yellow Band })}
\end{aligned}
$$$$
\text { NDVI }=\frac{(\text { NIR2 Band }- \text { Red Edge Band) }}{(\text { NIR2 Band }+ \text { Red Edge Band })} \quad \text { (Mutanga et al, 2012) (6) }
$$$$
\text { (Wolf, 2012) (7) }
$$

The thematic map, which was produced from Planetscope satellite image, by RB technique was shown Fig.5. 


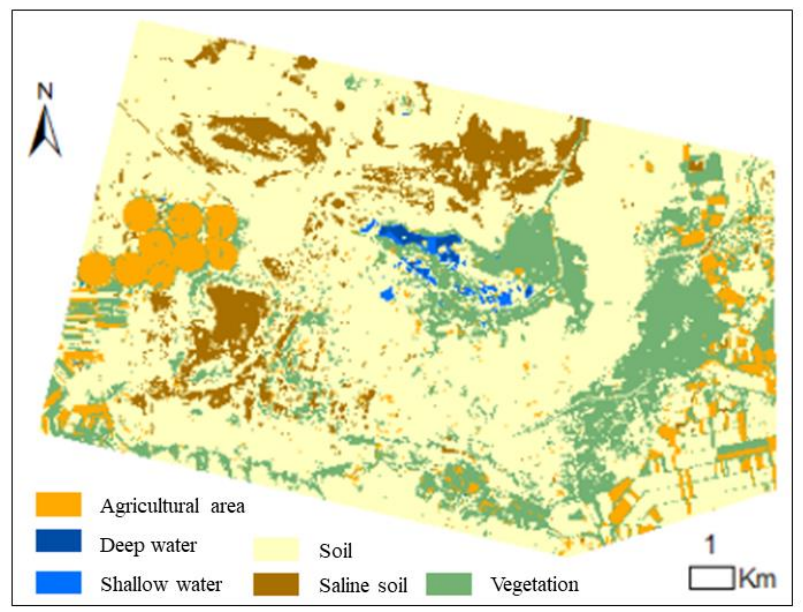

Figure 5. a) Thematic map produced from Planetscope with rule based classifier.

The thematic map produced from Worldview-3 satellite image, by RB technique was shown Fig.6.

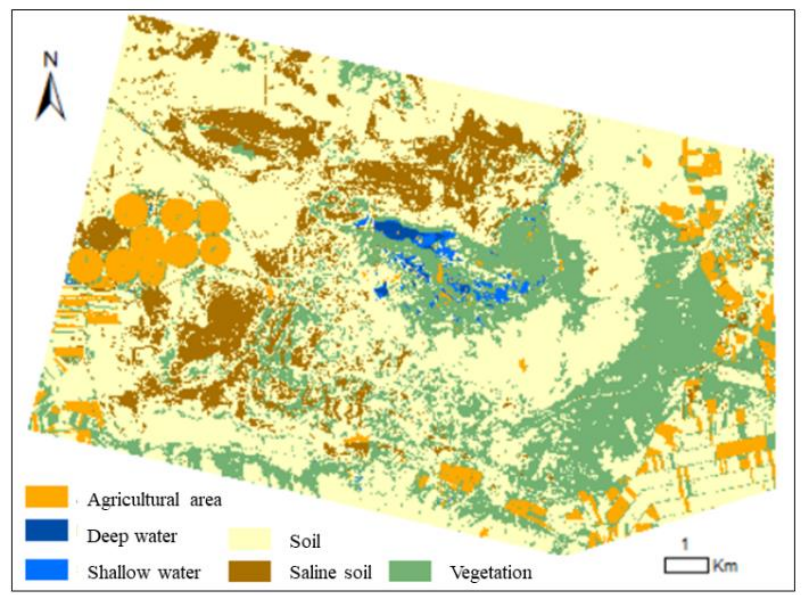

Figure 6. a) Thematic map produced from Worldview-3 with rule based classifier.

Vapnik, (1999) stated that SVM is a classifier separating two classes by optimizing the margin between classes. In order to create a model for Worldview-3 dataset, samples having 8 features, coastal, blue, green, yellow, red, red edge, NIR1, and NIR2 bands, were used as dataset. In similar way, blue, green, red and NIR bands were used as features for generating a classifier model for Planetscope. K-fold cross validation technique was used to divide the data into two groups; training and test. K parameter was selected as 10. A radial basis kernel function was used with SVM. Trial and error method were inadequate to determine the best hyperparameters of RBF kernel, which were cost and gamma. Thus, cost parameter was determined by optimization by taking into consideration of highest overall accuracy. Thematic maps produced from Planetscope and Worldview-3 satellite images with SVM classifier were shown in Fig.7 and Fig.8, respectively.

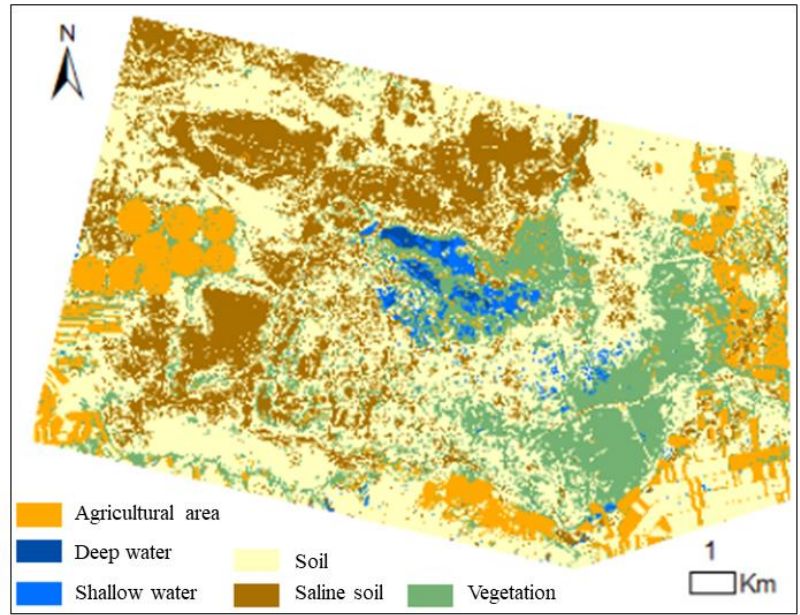

Figure 7. a) Thematic map produced from Planetscope with SVM classifier.

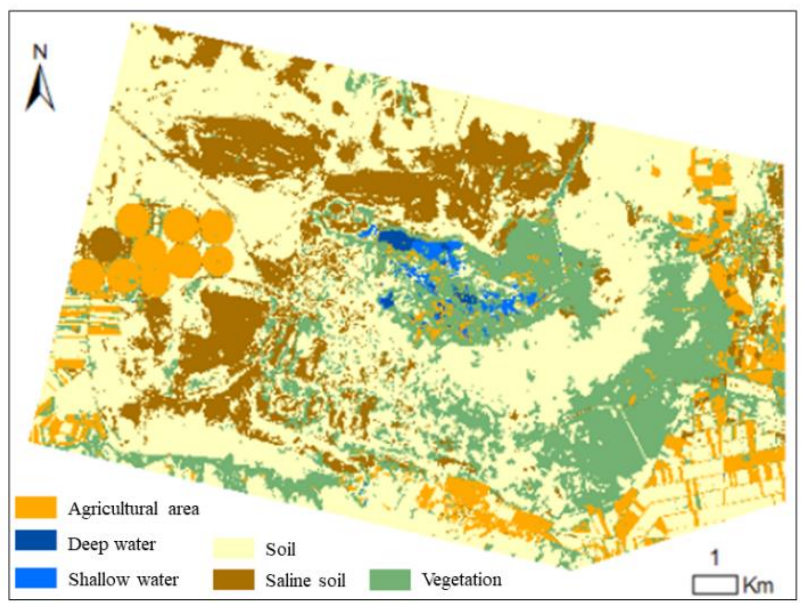

Figure 8. a) Thematic map produced from Worldview-3 with SVM classifier

\subsection{Results}

Generating error matrixes is an efficient method to assess the accuracy of produced maps (Congalton, 2008). Based on this research, error matrixes were produced in the study. For accuracy assessment, 120 points were selected These points remained same in accuracy assessment process of all of the produced maps. After the evaluation overall accuracies were computed. Overall accuracies of produced maps were shown in Table.1.

\begin{tabular}{|l|c|c|}
\hline Overall accuracy & Rule Based & Support Vector Machines \\
\hline Planetscope & $87 \%$ & $93 \%$ \\
\hline Worldview-3 & $94 \%$ & $96 \%$ \\
\hline
\end{tabular}

Table 1. Overall accuracies of produced maps

When the results were examined, it was seen that the highest accuracy was obtained from the thematic map produced from Worldview-3 with SVM classifier. In addition, from the thematic map produced from Planetscope with RB classifier gave the lowest accuracy among them. The reason of these results were having higher spectral and spatial resolution of Worldview-3 satellite image when it was compared with Planetscope image. Although Planetscope gave the lowest accuracy, it is an adequate tool to classify the area. Akgol wetland is a shallow wetland and 
its maximum depth is $1 \mathrm{~m}$. The effect of this situation can be seen in results. When the results were examined, deep water and shallow water areas were confused.

\section{CONCLUSIONS}

After the classification, accuracy assessment was done to measure the reliability of produced maps. The accuracy assessment was done among produced 4 land use / cover maps. For that purpose, error matrixes of maps were generated. According to overall accuracies of maps, both of the two techniques and satellite images were adequate to classify the study area. Although the accuracies were similar, the maps that were generated by SVM method gave higher accuracies than the maps that were generated by RB method. Besides that, the accuracy of maps that generated from Worldview-3 image were higher than the maps that generated from Planet images. Results show that having higher spectral and spatial improves the classification. However, it was also seen that if Worldview-3 satellite image can't be acquired on field survey day, Planetscope image can be used to classify the area. In addition its high accuracy, it provides image although the weather is cloudy. In addition, it can be predicted that if Worldview-3 image can be acquired on the field survey day, the accuracy of the thematic maps produced from it would be higher.

\section{ACKNOWLEDGEMENTS}

I would like to acknowledge the financial support of the Scientific and Technological Research Council of Turkey under project number TUBITAK-116Y142, and also Istanbul Technical University Scientific Projects Office (BAP) under project number MYL-2018-41650.

\section{REFERENCES}

Aguilar, M. A., Saldaña, M. M., \& Aguilar, F. J. (2013). GeoEye1 and WorldView-2 pan-sharpened imagery for object-based classification in urban environments. International Journal of Remote Sensing, 34(7), 2583-2606.

CCIWR, 2016, Climate Change Impact on Water Resources Project, Ministry of Forestry and Water Affairs, General Directorate of Water Management [Online]. Available: http://iklim.ormansu.gov.tr/Eng/

Congalton, R. G., \& Green, K. (2008). Assessing the accuracy of remotely sensed data: principles and practices. CRC press.

Dervisoglu, A., Musaoglu, N., Tanik, A., Seker, D. Z., \& Kaya, S. (2017). Satellite-based temporal assessment of a dried lake: case study of Akgol Wetland. Fresenius Environmental Bulletin, 26(1), 352-359.

Douaoui, A. E. K., Nicolas, H., \& Walter, C. (2006). Detecting salinity hazards within a semiarid context by means of combining soil and remote-sensing data. Geoderma, 134(1-2), 217-230.

Forkuor, G., Dimobe, K., Serme, I., \& Tondoh, J. E. (2018). Landsat-8 vs. Sentinel-2: examining the added value of sentinel2's red-edge bands to land-use and land-cover mapping in Burkina Faso. GIScience \& Remote Sensing, 55(3), 331-354.
Hamedianfar, A., \& Shafri, H. Z. M. (2015). Detailed intra-urban mapping through transferable OBIA rule sets using WorldView2 very-high-resolution satellite images. International Journal of Remote Sensing, 36(13), 3380-3396.

Huete, A. R. (1988). A soil-adjusted vegetation index (SAVI). Remote sensing of environment, 25(3), 295-309.

Kääb, A., Altena, B., \& Mascaro, J. (2017). Coseismic displacements of the 14 November $2016 \mathrm{Mw} 7.8$ Kaikoura, New Zealand, earthquake using the Planet optical cubesat constellation. Natural hazards and earth system sciences, 17, 627-639.

Luo, Y., Guan, K., \& Peng, J. (2018). STAIR: A generic and fully-automated method to fuse multiple sources of optical satellite data to generate a high-resolution, daily and cloud-/gapfree surface reflectance product. Remote Sensing of Environment, 214, 87-99.

Mathieu, R., Aryal, J., \& Chong, A. (2007). Object-based classification of Ikonos imagery for mapping large-scale vegetation communities in urban areas. Sensors, 7(11), 28602880 .

McCoy, R. M. (2005). Field methods in remote sensing. Guilford Press, 12-15.

McFeeters, S. K. (1996). The use of the Normalized Difference Water Index (NDWI) in the delineation of open water features. International journal of remote sensing, 17(7), 14251432.

Musaoglu, N., Tanik, A., Gumusay, M.Ü., Dervisoglu, A., Bilgilioglu, B.B., Yagmur, N., Bakirman, T., Baran, D., Gokdag, M.F., Long-term monitoring of wetlands via remote sensing and GIS: A case study from Turkey, 2. International Conference on Climate Change (ICCC 2018), 15-16 February 2018, Sri Lanka.

Mutanga, O., Adam, E., \& Cho, M. A. (2012). High density biomass estimation for wetland vegetation using WorldView-2 imagery and random forest regression algorithm. International Journal of Applied Earth Observation and Geoinformation, 18, 399-406.

Puetz, A. M., Lee, K., \& Olsen, R. C. (2009, April). WorldView2 data simulation and analysis results. In Algorithms and Technologies for Multispectral, Hyperspectral, and Ultraspectral Imagery XV (Vol. 7334, p. 73340U). International Society for Optics and Photonics.

Rouse Jr, J., Haas, R. H., Schell, J. A., \& Deering, D. W. (1974). Monitoring vegetation systems in the Great Plains with ERTS. In 3rd ERTS Symposium, NASA SP-351 I, pp. 309-317.

Url-1:<https://earth.esa.int/web/guest/-/worldview-3-fullarchive-and-tasking >, retrived date 08.03.2019

Url-2:<

https://assets.planet.com/docs/Planet_Combined_Imagery_Pro duct_Specs_letter_screen.pdf>, retrived date 02.04.2019

Vapnik, V. (1999). The nature of statistical learning theory. Springer science $\&$ business media.

Wan, S., \& Chang, S. H. (2018). Crop classification with WorldView-2 imagery using Support Vector Machine comparing texture analysis approaches and grey relational analysis in Jianan Plain, Taiwan. International Journal of Remote Sensing, 1-17. 
Wicaksono, P., \& Lazuardi, W. (2018). Assessment of PlanetScope images for benthic habitat and seagrass species mapping in a complex optically shallow water environment. International Journal of Remote Sensing, 39(17), 5739-5765.

Wolf, A. F. (2012, May). Using WorldView-2 Vis-NIR multispectral imagery to support land mapping and feature extraction using normalized difference index ratios. In Algorithms and Technologies for Multispectral, Hyperspectral, and Ultraspectral Imagery XVIII (Vol. 8390, p. 83900 N). International Society for Optics and Photonics.

Xian, G. Z. (2015). Remote sensing applications for the urban environment. CRC Press, 7-22.

Xie, C., Huang, X., Zeng, W., \& Fang, X. (2016). A novel water index for urban high-resolution eight-band WorldView-2 imagery. International journal of digital earth, 9(10), 925-941.

Xu, H. (2013). Rule-based impervious surface mapping using high spatial resolution imagery. International Journal of Remote Sensing, 34(1), 27-44. 